\title{
Porous Epoxy: Effect of Mixing Sequences (ELH versus EHL) Using Toluene as Extraction Medium via Ultrasonic Technique
}

\author{
Siti Noorkhartina Ishak, Pei Leng Teh, Uy Lan Du Ngoc, and Cheow Keat Yeoh \\ School of Materials Engineering, University Malaysia Perlis, Taman Muhibah, 02600 Jejawi, Perlis, Malaysia \\ Correspondence should be addressed to Siti Noorkhartina Ishak; khartina2209@gmail.com
}

Received 9 September 2015; Accepted 19 January 2016

Academic Editor: Atsushi Sudo

Copyright ( 2016 Siti Noorkhartina Ishak et al. This is an open access article distributed under the Creative Commons Attribution License, which permits unrestricted use, distribution, and reproduction in any medium, provided the original work is properly cited.

\begin{abstract}
Porous epoxy was fabricated using natural rubber latex (NRL) as the void template. In this study, two mixing sequences were selected: epoxy, hardener, and then latex (EHL) and epoxy, latex, and then hardener (ELH). The extraction process was carried out to extract the latex particles from the cured epoxy sample using toluene as extraction medium with ultrasonic technique for 1 hour. The formation of porous structure in epoxy system is dependent essentially on the amount of latex removed from the epoxy matrix. As expected, the density results showed lower values in the porous epoxy in ELH mixing sequences. More porous structure in epoxy was obtained which was proven by the increasing in porosity $\%$ which has led to lowering of the value in dielectric constant which is preferred for electronic packaging application. However, it also caused a decrease in flexural strength and modulus.
\end{abstract}

\section{Introduction}

Recently, porous materials have received increasing attentions in the fields of electronics, photonics, and life science [13]. Epoxy resin has been widely used in electronic packaging industries due to their ease of processing and low cost. Epoxy resin has been widely used by many researchers due to their excellent heat, moisture, and chemical resistance [4-6]. Low dielectric constant (low $k$ ) materials are the subject of intense investigation and development in order to replace conventional $\mathrm{SiO}_{2}$ dielectrics for the manufacturing of future generation microelectronic devices $[7,8]$. The primary method of lowering the dielectric constant is to make the dielectric film less dense by introducing porosity [9]. There are two fundamental routes to porosity in polymers: either blowing due to sudden gas expansion (as with polymer foams) or the removal of one or more disperse phases [10]. This paper utilized the latter, which encompassed the technique to form porous epoxy based on template method by a mixture with epoxy, polyamine hardener, and latex to produce disperse phase in an epoxy matrix, and then removed the dispersed by extraction using toluene as extraction. The advantages of the present technique over other methods are severalfold. First, the chemistry is limited to only three or four inexpensive chemicals, all of which are relatively stable to water and oxygen, relatively nontoxic, and very forgiving to alterations of the preparation method [11]. Second, the porous structure produced by the present template method can be easily adjusted by controlling the viscosity of latex to produce smaller pores. Third, the epoxy and polyamine used in this study are available in a wide range of molecular weights and can be easily exchanged to induce significant changes in the mechanical and electrical properties of the final epoxy [12]. Ultimately, the purpose of this paper is to highlight a simple method to introduce porosity in epoxy system in order to lower the dielectric constant.

\section{Materials and Method}

2.1. Materials. Epoxy DER 331 and polyamide A062 were supplied by Euro Chemo-Pharma Sdn. Bhd. Natural rubber latex was supplied by Grtah Hindus Sdn. Bhd. Epoxy DER 331 has an epoxide equivalent weight of 182-192 g/eq. Polyamide A062 as a curing agent has 110 equivalent per $\mathrm{H}$ active. Toluene 2,4-diisocyanate was obtained from Merck Schuchardt OHG, Germany, with density of $1.22 \mathrm{~g} / \mathrm{cm}^{3}$. 
2.2. Sample Preparation. The epoxy resin, hardener, and latex were added according to $100 \mathrm{phr}, 60 \mathrm{phr}$, and $0.5 \mathrm{phr}$, respectively. The latex content was fixed from 0.5 to $2.0 \mathrm{phr}$. The first series was followed by the sequences of epoxy, hardener, and then latex (EHL). The second series was followed by the sequences of epoxy, latex, and then hardener (ELH). Epoxy resin and hardener were stirred using mechanical stirrer and then latex was added using dropper until homogenous. After that, the mixture was put in container and placed in oven for curing at $100^{\circ} \mathrm{C}$ for 1 hour.

2.3. Formation of Porous Structure. The samples were immersed in toluene using ultrasonic technique for 60 minutes. Porous structure formed once the latex was extracted out.

2.4. SEM. The morphology of the fracture surface was observed using scanning electron microscope (SEM) model JSM-6460LA. The cross section of the SEM specimen was sputter coated with a thin layer of palladiums using the auto fine coater, model JEOL JFC 1600.

2.5. Density. The relative density and total pore volume of the porous structure were determined using ACCUPYC II 1340 Gas Displacement Pycnometer according to ASTM D6226.

2.6. Porosity. Based on density data, the porosity was determined using

$$
\begin{aligned}
\text { Porosity } \% & =\left(1-\frac{\text { density porous }}{\text { density bulk }}\right) \times 100 \% \\
& =\left(1-\frac{\rho_{1}}{\rho_{0}}\right) \times 100 \%
\end{aligned}
$$

where $\rho_{0}$ and $\rho_{1}$ are the densities of the dense polymer and the porous epoxy, respectively.

2.7. Mechanical Properties. The flexural test was done according to ASTM D790 using a universal testing machine Instron 5560. The test was done at a crosshead speed of $5 \mathrm{~mm} / \mathrm{min}$. The specimen was cut to the required dimension of $60 \mathrm{~mm} \times$ $13 \mathrm{~mm} \times 3 \mathrm{~mm}$.

2.8. Dielectric Constant. The dielectric measurement was performed using impedance gain/phase analyzer (Solartron 1260 ) in the frequency range of $1 \mathrm{kHz}$ to $1 \mathrm{MHz}$ at room temperature:

\section{Dielectric constant}

$$
=\frac{\text { Capacitance, material as dielectric }}{\text { Capacitance, air or vacuums as dielectric }} \text {. }
$$

\section{Results and Discussion}

3.1. Porosity. Figure 1 shows the porosity percentage (\%) of porous epoxy. Porous epoxy using both ELH and EHL mixing sequences shows increasing trend in porosity \%. As seen in

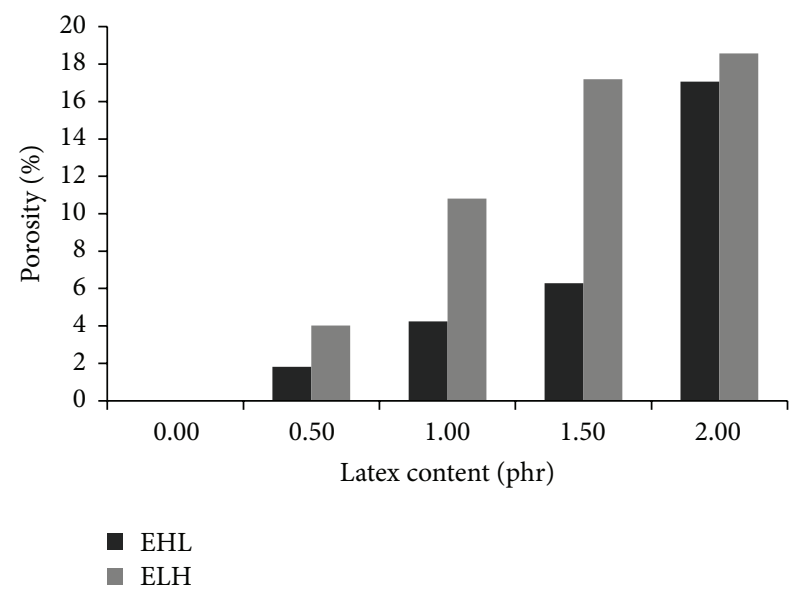

FIGURE 1: Porosity \% of porous epoxy extracted by toluene using mixing sequence of EHL and ELH, respectively.

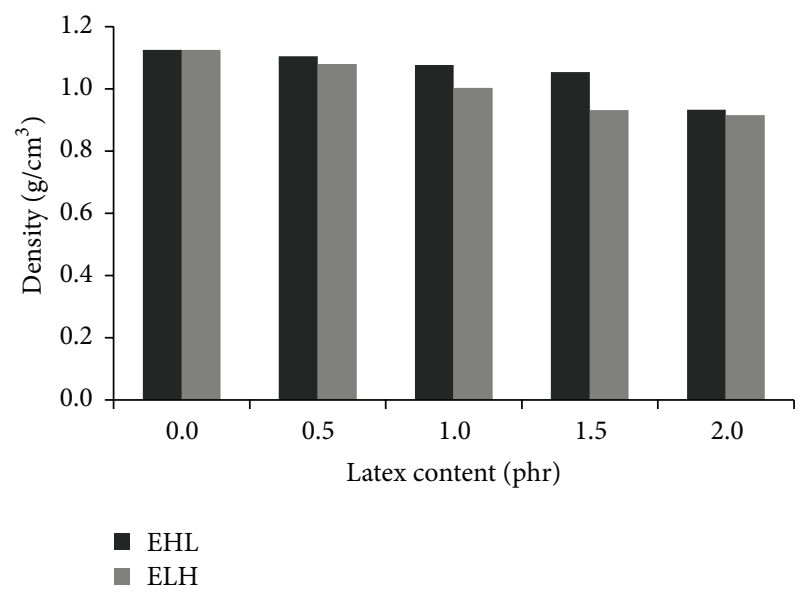

FIGURE 2: Density of porous epoxy extracted by toluene using mixing sequence of EHL and ELH, respectively.

the figure, ELH mixing sequence shows higher porosity \%. It was postulated that higher porosity means that more porous structure was produced. The data is in line with the flexural properties result which will be discussed in Section 3.3; it is clear that the bending strength and modulus decreased with increasing porosity, which is the decrease of carrying capacity of materials. This typical behavior has been reported by many researchers, and it has been vaguely explained that the densification is assumed to cause relief in the stress concentration in the defects $[13,14]$.

3.2. Density. Figure 2 shows the density of porous epoxy with different latex content. The density increased with increasing of latex content. The density of ELH is lower compared to EHL mixing sequence at the same latex content. When more latex was extracted, more porous structure will be formed, and then the density reduced. This is in agreement with Hemmasi et al.; the density reduction is related to the void content achieved in polymer matrix [15]. 


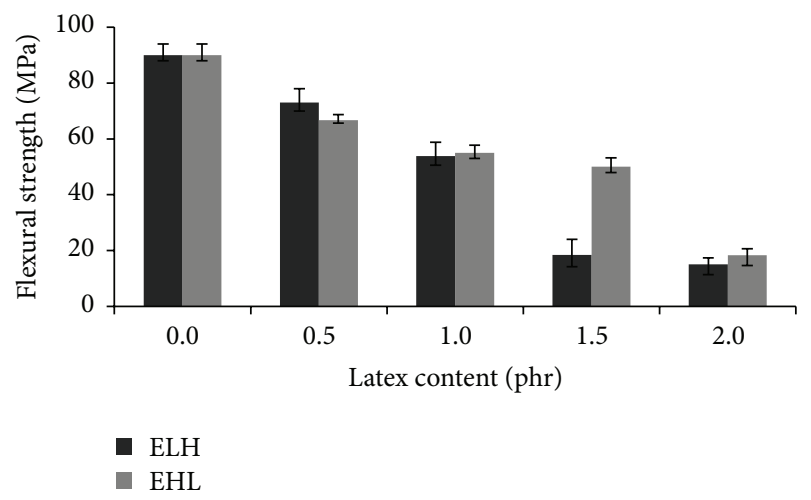

FIGURE 3: The flexural strength of porous epoxy extracted by toluene using mixing sequence of EHL and ELH, respectively.

3.3. Flexural Properties. Figure 3 shows the effect of latex content on porous epoxy with different mixing sequences using ultrasonic technique. As shown in the figure, flexural strength for both mixing sequences decreased with the increase of latex content. The mixing sequences for epoxy, latex, and then hardener (ELH) show the lower value compared to epoxy, hardener, and then latex (EHL). It can be observed that the flexural strength of mixing sequence ELH exhibited lower flexural strength as compared to mixing sequence ELH at the same latex content at $1.0,1.5$, and $2.0 \mathrm{phr}$, respectively. It is believed that the quantity of porous structure in porous epoxy produced following the sequence of ELH is higher as compared to mixing sequence EHL. This can be explained using the density results which was discussed in Section 3.2. During ultrasonic process, latex particle was extracted from the epoxy to form a porous structure. The lower value means that more latex particle was extracted from the epoxy and formed voids or holes; thus no reinforcing effect is expected $[16,17]$. As stress applied to the porous epoxy, it cannot be transferred through the voids nor could the voids absorb the energy, and it thus acted as stress concentration point.

Figure 4 shows the SEM micrograph of flexural fracture surface of the porous epoxy. Porous epoxy followed by the mixing sequence of ELH (Figure 4(a)) has smaller and more porous structure compared to EHL. The dispersion of latex in ELH mixing sequences is more dispersed because no crosslinking occurred between epoxy and latex when latex was added to epoxy before the addition of hardener. Thus it produced smaller particles which can be easily extracted using toluene. This led to decrease in density and increase in percentage of porosity, therefore reducing the total ability of the porous epoxy to absorb load during fracture.

The flexural modulus of porous epoxy is shown in Figure 5. The data reveals that the flexural modulus of all latex content decreased with increasing in latex content in the porous epoxy. It can be seen that more voids were obtained by increasing the latex content of the porous epoxy. At the same time, more stress concentrators are introduced to the material. These stress concentrators initiated many weak points in the material that aid in lowering the mechanical properties of the composites.

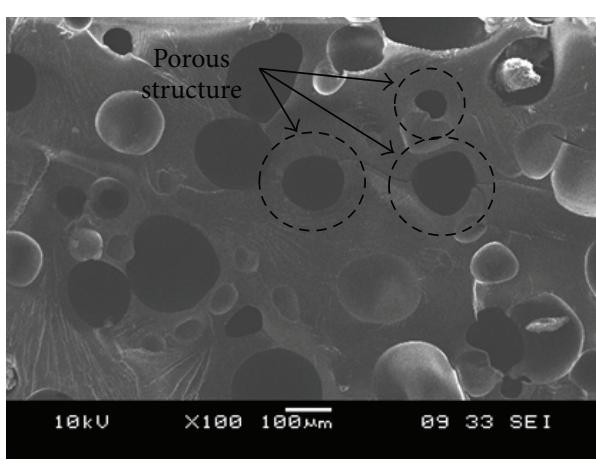

(a)

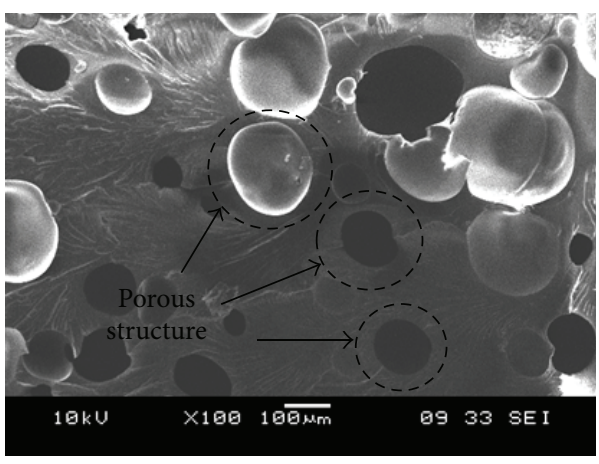

(b)

FIGURE 4: SEM micrograph showing the flexural fracture surface morphology of porous epoxy at $2.0 \mathrm{phr}$ latex in mixing sequences: (a) epoxy, latex, and then hardener (ELH) and (b) epoxy, hardener, and then latex (EHL), respectively.

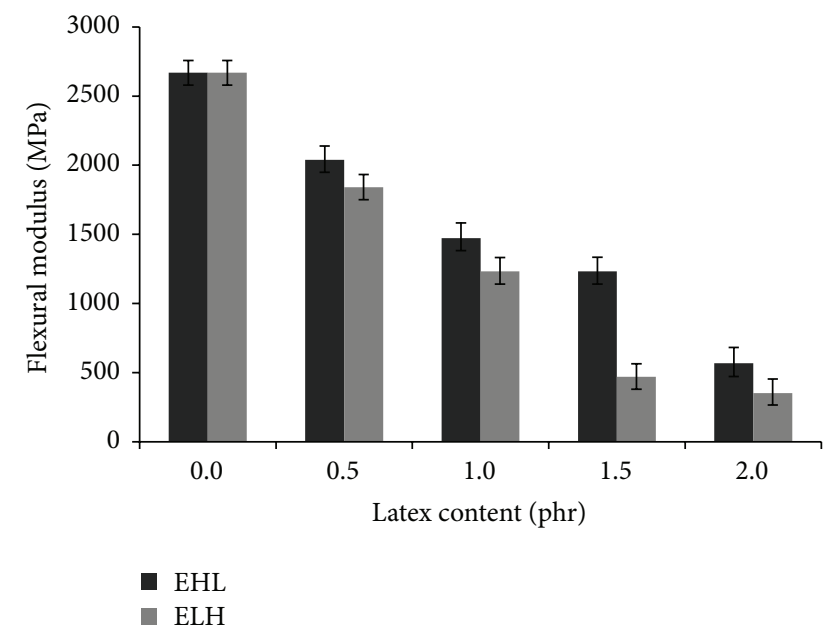

Figure 5: The flexural modulus of porous epoxy extracted by toluene using mixing sequence of EHL and ELH, respectively.

3.4. Dielectric Constant. Figures 6 and 7 show dielectric constant value with different latex content at different mixing sequences. As shown in both figures, dielectric constant decreased when the latex content was increased. The more porous structure caused the porous epoxy to have low dielectric constant. The dielectric constant is predicted to drop even 


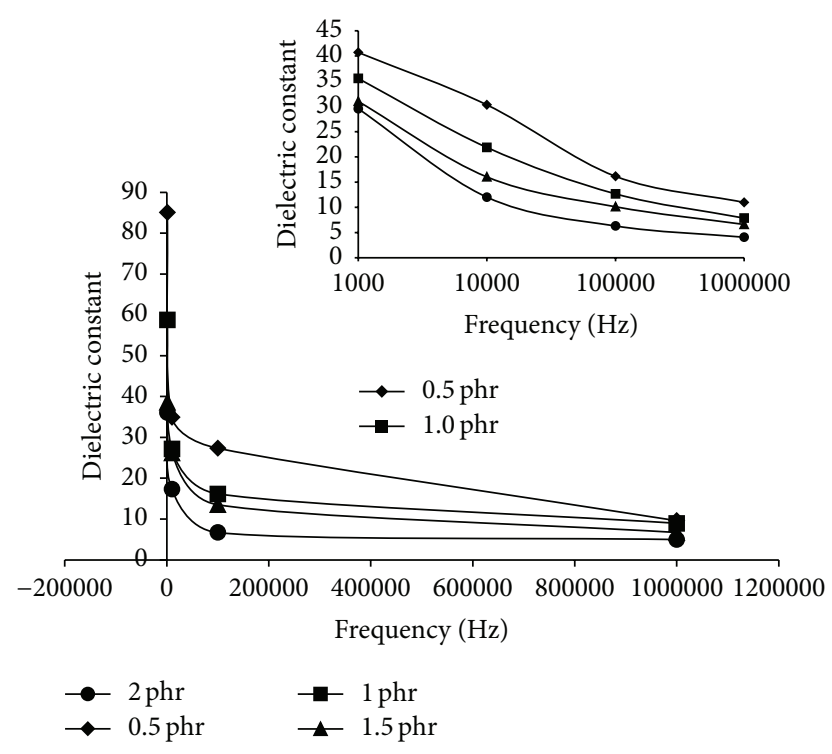

FIGURE 6: The dielectric constant of porous epoxy for epoxy, latex, and hardener (ELH) mixing by ultrasonic technique.

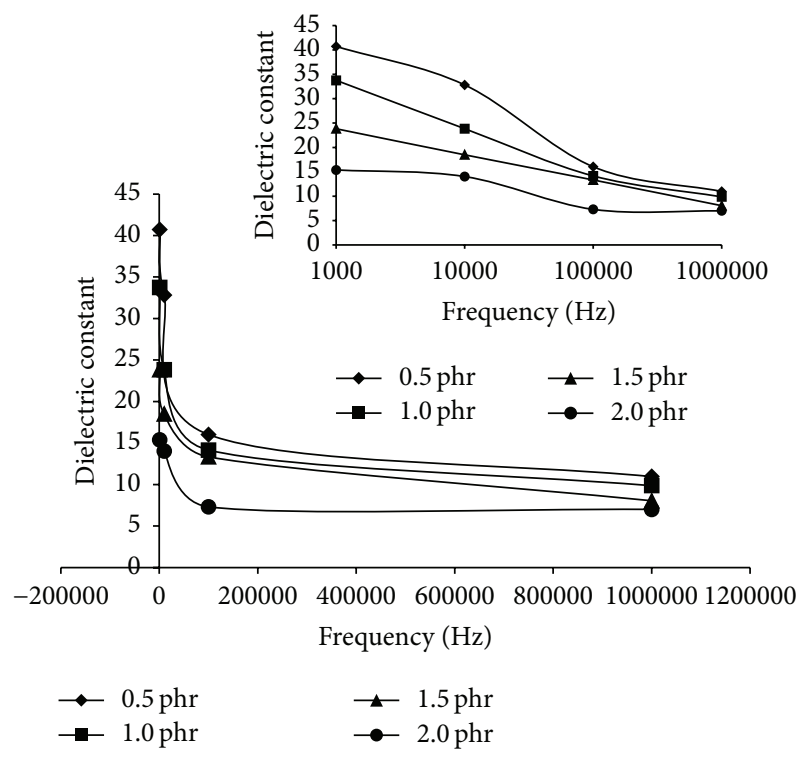

FIGURE 7: The value of dielectric constant of porous epoxy for epoxy, hardener, and latex (EHL) mixing by ultrasonic technique.

lower when the latex content is higher. In view of the strong correlation between the increase in porous structure and the decrease in the dielectric constant, it can be concluded that the main microstructural parameter affecting the dielectric constant is the porosity of the samples. Low polymer volume fractions result in a low dielectric constant, presumably because of the residual porosity of the porous epoxy [18, 19]. Also in previous study, the increasing in frequency results in decreasing in dielectric constant. The dielectric constant value also decreased with increasing frequency for both mixing compositions. Table 1 shows the value of dielectric constant at $2.0 \mathrm{phr}$ of latex content. Larger changes
TABLE 1: Dielectric constant value of porous epoxy at $10^{3}$ and $10^{6}$.

\begin{tabular}{lcc}
\hline Mixing sequence & $10^{3} \mathrm{~Hz}$ & $10^{6} \mathrm{~Hz}$ \\
\hline ELH & 36.75 & 5.01 \\
EHL & 48.56 & 8.59 \\
\hline
\end{tabular}

of dielectric constant were observed from $10^{3}$ to $10^{6}$. These results were attributed to the increase in the amount of latex in ELH mixing sequences. Banjuraizah et al., 2010, stated that a material with a low dielectric constant has a great advantage to be used in high speed integrated circuit substrate since a low dielectric constant will increase signal transmission speeds by decreasing the propagation delay [20].

\section{Conclusion}

Porous epoxy thermosets were successfully prepared and compared between mixing sequences of epoxy/latex/hardener (ELH) and epoxy/hardener/latex (EHL) using toluene as extraction medium with ultrasonic technique. Overall ELH mixing sequences showed the higher porosity as compared to EHL mixing sequences and it can be concluded that ELH is the better mixing sequence in forming the porous epoxy. As the latex content increased from $0 \mathrm{phr}$ to $2.0 \mathrm{phr}$, the microstructure of the epoxy systems changed from dense to porous. Both the flexural strength and modulus for porous epoxy decreased with increasing the latex content. This was due to the increase in porosity \% in the porous epoxy and correlated well with morphological observations obtained by SEM. Lastly, dielectric constant value for porous epoxy was found to decrease with decrease in the density of material.

\section{Conflict of Interests}

The authors declare that there is no conflict of interests regarding the publication of this paper.

\section{Acknowledgment}

The financial support of Fundamental Research Grant Scheme (FRGS) Grant no. 9003-00472 is gratefully acknowledged.

\section{References}

[1] B.-L. Su, C. Sanchez, and X.-Y. Yang, Eds., Hierarchically Structured Porous Materials: From Nanoscience to Catalysis, Separation, Optics, Energy, and Life Science, John Wiley \& Sons, Hoboken, NJ, USA, 2nd edition, 2011.

[2] M. S. Silverstein, N. R. Cameron, and M. A. Hillmyer, Porous Polymer, John Wiley \& Sons, Hoboken, NJ, USA, 2011.

[3] K. Vafai, Handbook of Porous Media, CRC Press, New York, NY, USA, 2000.

[4] C.-C. Hsu, K.-C. Chang, T.-C. Huang et al., "Preparation and studies on properties of porous epoxy composites containing microscale hollow epoxy spheres," Microporous and Mesoporous Materials, vol. 198, pp. 15-21, 2014. 
[5] P. L. Teh, M. Mariatti, H. M. Akil et al., "The properties of epoxy resin coated silica fillers composites," Materials Letters, vol. 61, no. $11-12$, pp. $2156-2158,2007$.

[6] D. N. U. Lan, A. Abu Bakar, B. Azahari, Z. M. Ariff, and Y. Chujo, "Effect of interlocking between porous epoxy microparticles and elastomer on mechanical properties and deformation modes," Polymer Testing, vol. 31, no. 7, pp. 931-937, 2012.

[7] D.-D. Guo, J.-W. Jiang, Y.-J. Liu, X.-L. Liu, and S.-R. Sheng, "New fluorinated xanthene-containing polybenzoxazoles with low dielectric constants," Journal of Fluorine Chemistry, vol. 175, pp. 169-175, 2015.

[8] M. A. Worsley, M. Roberts, S. F. Bent et al., "Detection of open or closed porosity in low- $\kappa$ dielectrics by solvent diffusion," Microelectronic Engineering, vol. 82, no. 2, pp. 113-118, 2005.

[9] C.-C. Cho, D. M. Smith, and J. Anderson, "Low dielectricconstant insulators for electronics applications," Materials Chemistry \& Physics, vol. 42, no. 2, pp. 91-95, 1995.

[10] C. Torres-Sanchez and J. R. Corney, "Effects of ultrasound on polymeric foam porosity," Ultrasonics Sonochemistry, vol. 15, no. 4, pp. 408-415, 2008.

[11] S. Yu, H. Hu, J. Ma, and J. Yin, "Tribological properties of epoxy/rubber nanocomposites," Tribology International, vol. 41, no. 12, pp. 1205-1211, 2008.

[12] M. Rutnakornpituk, "Modification of epoxy-novolac resins with polysiloxane containing nitrile functional groups: synthesis and characterization," European Polymer Journal, vol. 41, no. 5, pp. 1043-1052, 2005.

[13] X.-L. Liao, W.-F. Xu, Y.-L. Wang, B. Jia, and G.-Y. Zhou, "Effect of porous structure on mechanical properties of C/PLA/nanoHA composites scaffold," Transactions of Nonferrous Metals Society of China (English Edition), vol. 19, no. 3, pp. s748-s751, 2009.

[14] A. Shyam, G. Bruno, T. Watkins et al., "The effect of porosity and microcracking on the thermomechanical properties of cordierite," Journal of the European Ceramic Society, vol. 35, no. 16, pp. 4557-4566, 2015.

[15] A. H. Hemmasi, H. Khademi-Eslam, S. Pourabbasi, I. Ghasemi, and M. Talaiepour, "Cell morphology and physico-mechanical properties of HDPE/EVA/RICE HULL hybrid foamed composites," BioResources, vol. 6, no. 3, pp. 2291-2308, 2011.

[16] Y. Li, Q. Li, and H. Ma, "The voids formation mechanisms and their effects on the mechanical properties of flax fiber reinforced epoxy composites," Composites A: Applied Science and Manufacturing, vol. 72, pp. 40-48, 2015.

[17] S. R. Dhanushuki, F. Capitanio, T. Briggs, and W. Mérida, "Understanding flexural, mechanical and physico-chemical properties of gas diffusion layers for polymer membrane fuel cell and electrolyzer systems," International Journal of Hydrogen Energy, vol. 40, no. 46, pp. 16846-16859, 2015.

[18] J.-P. Hsu, S.-H. Hung, and W.-C. Chen, "A theoretical model on pore size distribution in low dielectric constant nanoporous silica films," Thin Solid Films, vol. 473, no. 2, pp. 185-190, 2005.

[19] Z. Hou, F. Ye, and L. Liu, "Effects of pore shape and porosity on the dielectric constant of porous $\beta$-SiAlON ceramics," Journal of the European Ceramic Society, vol. 35, no. 15, pp. 4115-4120, 2015.

[20] J. Banjuraizah, H. Mohamad, and Z. A. Ahmad, "Thermal expansion coefficient and dielectric properties of nonstoichiometric cordierite compositions with excess $\mathrm{MgO}$ mole ratio synthesized from mainly kaolin and talc by the glass crystallization method," Journal of Alloys and Compounds, vol. 494, no. 1-2, pp. 256-260, 2010. 

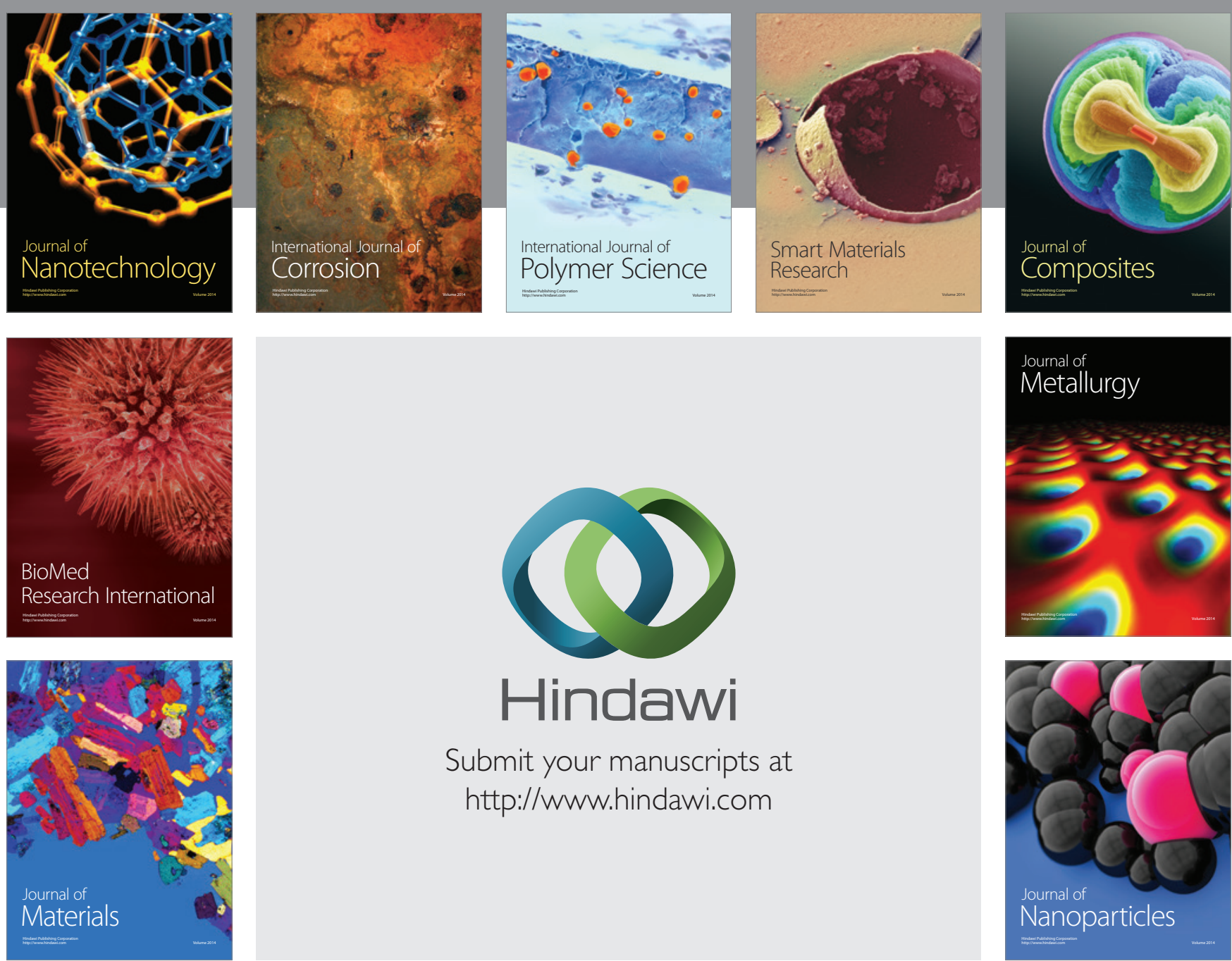

\section{Hindawi}

Submit your manuscripts at

http://www.hindawi.com

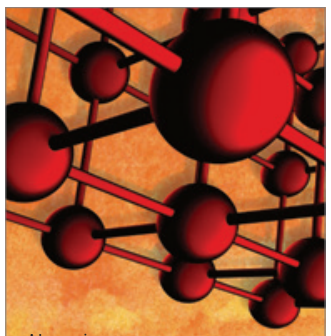

Materials Science and Engineering
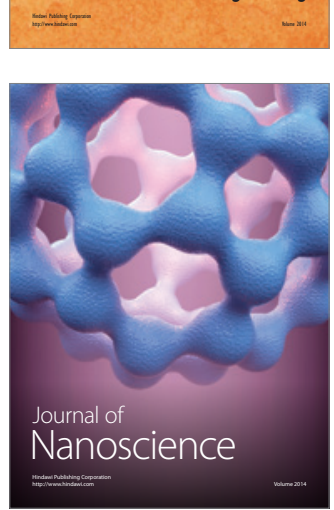
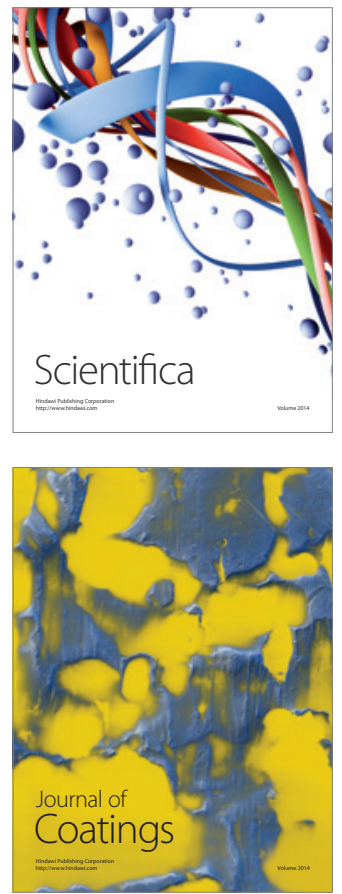
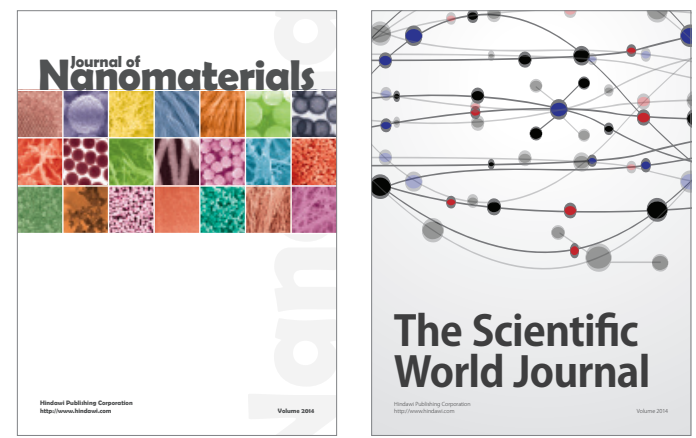

The Scientific World Journal
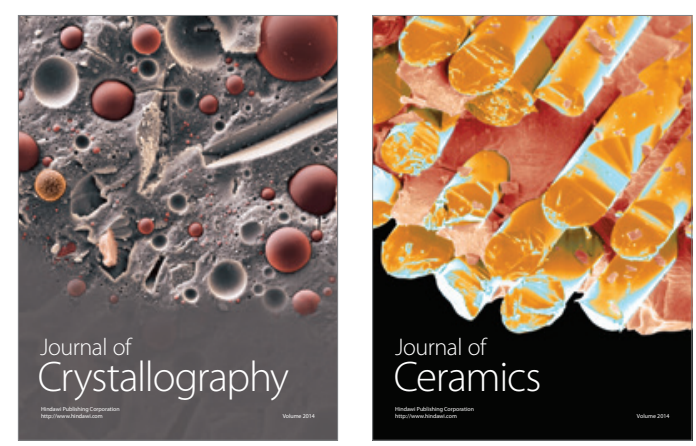
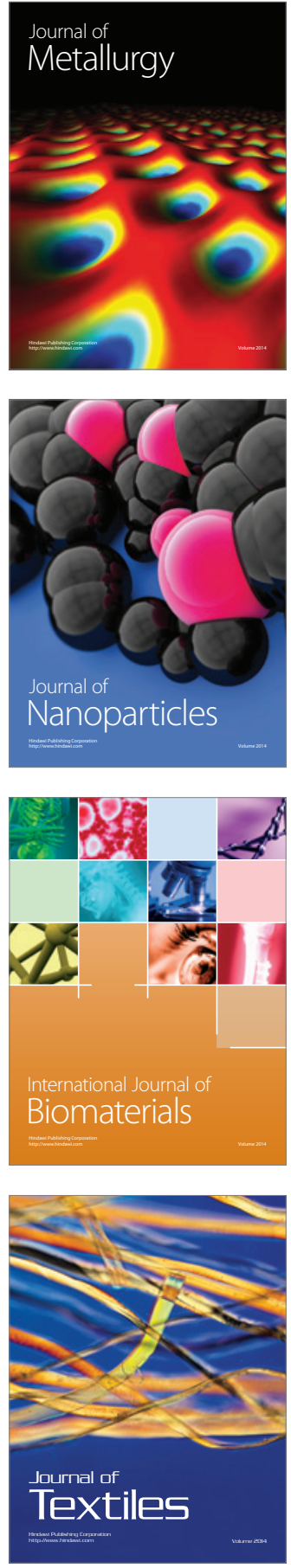